\title{
Correction to: Ultrasound in the Limited-Resource Setting: A Systematic Qualitative Review
}

\author{
Molly Hallweaver ${ }^{1} \cdot$ Christine McBeth $^{1} \cdot$ Lori Stolz $^{2} \cdot$ Amy C. Studer $^{3} \cdot$ Michael Schick $^{1}$
}

Published online: 23 July 2020

(C) Springer Science+Business Media, LLC, part of Springer Nature 2020

\section{Correction to: Curr Radiol Rep (2019) 7:21 \\ https://doi.org/10.1007/s40134-019-0331-y}

The original version of the article, unfortunately, contained a typographical error in one author's name in the author group. The author's name was published as 'Amy Struder' and the corrected name is 'Amy C. Studer'.
Publisher's Note Springer Nature remains neutral with regard to jurisdictional claims in published maps and institutional affiliations.

The original article can be found online at https://doi.org/10.1007/ s40134-019-0331-y.

This article is part of the Topical collection on Global Radiology.

Michael Schick

mschick@ucdavis.edu

1 Department of Emergency Medicine, University of California

Davis, Sacramento, CA, USA

2 Department of Emergency Medicine, University of

Cincinnati, Cincinnati, USA

3 University of California Davis, Davis, USA 